\title{
Synthesis and Characterization of Ultralong Copper Sulfide Nanowires and their Electrical Properties
}

Cosimo Anichini, ${ }^{a}$ Włodzimierz Czepa ${ }^{b, c}$ Alessandro Aliprandi, ${ }^{a}$ Valentina Girelli Consolaro, ${ }^{d}$ Ovidiu Ersen, ${ }^{d}$ Artur Ciesielski ${ }^{a, b, *}$ Paolo Samorì ${ }^{a^{*}}$

${ }^{a}$ Université de Strasbourg, CNRS, ISIS 8 allée Gaspard Monge, 67000 Strasbourg, France.

$$
\text { E-mail : ciesielski@unistra.fr, samori@unistra.fr }
$$

${ }^{b}$ Centre for Advanced Technologies, Adam Mickiewicz University, 61-614 Poznań, Uniwersytetu Poznańskiego 10, Poland.

${ }^{c}$ Faculty of Chemistry, Adam Mickiewicz University, Uniwersytetu Poznańskiego 8, 61-614 Poznań, Poland.

${ }^{d}$ Université de Strasbourg, CNRS, IPCMS, 23 rue du Loess, BP 43, 67034 Strasbourg Cedex 2, 


\begin{abstract}
We report the synthesis of ultralong copper sulfide nanowires $\left(\mathrm{Cu}_{2-\mathrm{x}} \mathrm{SNWs}\right)$ through the sulphidation reaction of metallic copper nanowires (CuNWs) by thiourea in mild conditions. The multiscale characterization of $\mathrm{Cu}_{2-x} \mathrm{SNWs}$ revealed the presence of a core shell structure made by an external covellite layer coating a roxbyite core. The $\mathrm{Cu}_{2-x} \mathrm{SNWs}$, exhibiting lengths as high as $200 \mu \mathrm{m}$, can be easily dispersed in ethanol and deposited onto arbitrary substrates such as glass or plastic. The resulting films are readily conducting without need of post- treatments and exhibit a sheet resistance of $4.1 \mathrm{k} \Omega / \mathrm{sq}$ at $73.7 \%$ transmittance (at $550 \mathrm{~nm}$ ), by virtue of the high aspect ratio of the $\mathrm{Cu}_{2-\mathrm{x}} \mathrm{SNWs}$. The multiscale electrical characterization down to the single $\mathrm{Cu}_{2-\mathrm{x}} \mathrm{SNWs}$ revealed a low resistivity of $6.9 \times 10^{-6} \Omega \cdot \mathrm{m}$ and perfectly Ohmic conduction. Interestingly, the conductivity of $\mathrm{Cu}_{2-x} \mathrm{SNWs}$ films supported on polyethylene naphthalate sheets remained almost unaltered ( $4 \%$ decrease) after 10000 bending cycles. In addition, $\mathrm{Cu}_{2-x} \mathrm{SNWs}$ have shown an excellent chemical stability towards a strong oxidant like $\mathrm{FeCl}_{3}$ as well as in acidic environment. Finally, $\mathrm{Cu}_{2-x} \mathrm{SNW}$ s have been employed as active materials in symmetric supercapacitors revealing good pseudocapacitive behaviour, with specific capacity as high as $324 \mathrm{~F} \cdot \mathrm{g}^{-1}\left(\right.$ at $5 \mathrm{mV} \cdot \mathrm{s}^{-1}$ ) and $70 \%$ retention of the initial capacitance after 5000 cycles (at $100 \mathrm{mV} \cdot \mathrm{s}^{-1}$ ).
\end{abstract}




\section{Introduction}

The ever-growing flexible, wearable electronics markets require a constant supply of conducting materials that can be processed at low-cost, on large-area and on various flexible substrates. Furthermore, for opto-electronic applications, transparency of thin conductive films is a coveted feature, e.g. due to the widespread request of curved/ foldable screens. Beyond carbon-based nanomaterials such as carbon nanotubes ${ }^{1}$ or graphene, ${ }^{2}$ metal nanowires have been considered as the next generation of flexible transparent conductors. ${ }^{3}$ Indeed, the high aspect ratio of metal nanowires allows them to exhibit a relatively low percolation threshold, which is beneficial for the fabrication of thin film conductive layers and devices for transparent electronics ${ }^{4}$ with enhanced mechanical properties. Among them, copper nanowires (CuNWs) has gained increasing attention in the last decade as they can be readily synthesized at extremely low cost and exhibit high processability. ${ }^{5}$ Furthermore, in view of the high transparency of the obtained CuNWs films, performance comparable to commercially available transparent conductive oxides such as indium tin oxide (ITO) can be reached. Regrettably, CuNWs are prone to oxidation, which limits their technological applications. In particular, the as-synthesized CuNWs exhibit native insulating oxide layer that needs to be removed to allow efficient charge percolation through CuNWs films and networks. Many efforts have been devoted to improve the electrochemical stability of copper through the formation of alloys, ${ }^{6}$ or by coating it protective shells. ${ }^{7}$ Unfortunately, such strategies require a post-processing of the material that not only increases the production cost, but could be incompatible with chemically fragile substrates such as paper or plastic. Therefore, it is of interest to obtain a material that can be used as an ink to be readily deposited onto an arbitrary substrate without any further treatment. In this regard copper sulfide, which has a general formula $\mathrm{Cu}_{2-x} S$, appears particularly appealing as it displays a remarkable chemical stability, while its electronic properties not only depend on the $\mathrm{Cu}: \mathrm{S}$ ratio, but also on its morphology at the nanoscale. ${ }^{8}$ Currently, $\mathrm{Cu}_{2-\mathrm{x}} \mathrm{S}$ is explored in a wide range of applications including solar cells, photocatalysis, biosensors, optoelectronic and is employed as a cathode material in lithium rechargeable batteries. ${ }^{9}$

Herein, we investigate the possibility to convert the native oxide layer $\left(\mathrm{Cu}_{x} \mathrm{O}_{y}\right)$ present on the CuNWs surface to copper sulfide $\left(\mathrm{Cu}_{2-\mathrm{x}} \mathrm{S}\right)$ while keeping the same high aspect ratio of the unmodified CuNWs to obtain a stable material that can be disperse and directly deposited onto a substrate without the need of any post deposition treatment. The resulting $\mathrm{Cu}_{2-x} \mathrm{SNWs}$ have been in-depth characterized with a wide range of physicochemical techniques to determine their composition and properties. The conductivity of the $\mathrm{Cu}_{2-x} \mathrm{SNWs}$ films has been correlated with the optical transparency, to evaluate their possible use as transparent conductors, and through bending test experiments to verify their adequacy in flexible electronics. The chemical stability of $\mathrm{Cu}_{2-x} \mathrm{SNWs}$ has been verified versus known copper etchant such as $\mathrm{FeCl}_{3}, \mathrm{HCl}$ and $\mathrm{NaOH}$. Finally, the $\mathrm{Cu}_{2-x} \mathrm{SNWs}$ have been exploited as active material in a solid-state symmetric supercapacitor revealing pseudocapacitive behavior and promising electrochemical performances.

\section{Materials and methods}




\section{$2.1 \mathrm{Cu}_{2-\mathrm{x}} \mathrm{S}$ Nanowires (NWs) synthesis}

First, CuNWs were synthesized following a modification of an existing method. ${ }^{10}$ To this end $380 \mathrm{mg}$ of $\mathrm{CuCl}_{2} \cdot 2 \mathrm{H}_{2} \mathrm{O}$ and $2.6 \mathrm{~g}$ of octadecylamine were dissolved in $110 \mathrm{~mL}$ of deionized water. The suspension was sonicated until a light blue emulsion was obtained. Then $850 \mathrm{mg}$ of glucose were added and the emulsion was stirred at $60{ }^{\circ} \mathrm{C}$ for 3 hours to homogenize the emulsion. Finally, the emulsion was transferred to a steel autoclave and heated to $115^{\circ} \mathrm{C}$ for 16 hours. The resulting CuNWs were isolated from the reaction suspension by centrifugation firstly with water, then with ethanol/water mixture 1/1, and finally with pure ethanol (4500 rpm, $8 \mathrm{~min}$ ).

To synthesize the $\mathrm{Cu}_{2-\mathrm{x}} \mathrm{SNWs}$, thiourea $(137 \mathrm{mg})$ and $\mathrm{CuCl}_{2} \cdot 2 \mathrm{H}_{2} \mathrm{O}(0.0$ or $1.0 \mathrm{mg})$ were dissolved in 55 $\mathrm{mL}$ of ethanol (or $55 \mathrm{~mL}$ of water). Then, $5 \mathrm{~mL}$ of CuNWs ethanolic suspension (1.2 $\mathrm{mg} \cdot \mathrm{mL}^{-1}$ ) were added to the solution and this was sonicated for $2 \mathrm{~min}$ to obtain a homogenous dispersion. Finally, the solution was heated at $80{ }^{\circ} \mathrm{C}$ without stirring for 2 hours. The obtained $\mathrm{Cu}_{2-x} \mathrm{SNWs}$ were then washed several times by centrifugation from ethanol to remove the excess of thiourea $(5000 \mathrm{rpm}, 10$ $\mathrm{min}$ ) and finally dispersed in $40 \mathrm{~mL}$ ethanol.

\subsection{Preparation of transparent conductive substrates based on $\mathrm{Cu}_{2-x} \mathrm{SNWs}$}

The $\mathrm{Cu}_{2-\mathrm{x}} \mathrm{SNW}$ s ethanolic dispersion was further diluted 20 times in ethanol, sonicated for $2 \mathrm{~min}$ and finally spray-coated with a commercial airbrush onto freshly cleaned soda lime glass slides, polyethylene terephthalate (PET) and polyethylene naphthalate (PEN) substrates (125 $\mu \mathrm{m}$ thick). To assess the transparency of the film as a function of its sheet resistance, increasing amounts of NWs dispersion were coated onto the substrates.

\subsection{Single $\mathrm{Cu}_{2-\mathrm{x}} \mathrm{S}$ Nanowire device fabrication}

A diluted suspension of $\mathrm{Cu}_{2-x} \mathrm{SNWs}$ in ethanol was sonicated for $5 \mathrm{~min}$ and then drop-casted onto a freshly cleaned $\mathrm{Si} / \mathrm{SiO}_{2}$ substrate with patterned gold markers. Then, the single $\mathrm{Cu}_{2-x} \mathrm{SNW}$ devices were patterned by direct laser lithography (AZ1505 photoresist and MIF726 developer, Micro Chemicals $\mathrm{GmbH}$, Italy) using the laser writer LW405B (Microtech srl, Italy). Afterwards, a uniform gold layer (60 $\mathrm{nm}$ ) was deposited on top by vacuum thermal evaporation, followed by a lift-off process in warm acetone $\left(50^{\circ} \mathrm{C}\right)$ to remove the unexposed photoresist and obtain the final source and drain electrodes.

\subsection{Assembly of the supercapacitor}

The working electrodes were prepared by mixing $\mathrm{Cu}_{2-\mathrm{x}} \mathrm{SNWs}(80 \% \mathrm{wt} \%, 8 \mathrm{mg})$, carbon black (10wt\%, $1 \mathrm{mg}$ ) and poly(tetrafluoroethylene) (PTFE) (10wt\%, $1 \mathrm{mg}$ ) in 2-3 drops of $\mathrm{N}$-Methyl-2-pyrrolidone. The paste was then deposited on carbon foil substrate and dried under vacuum $\left(80^{\circ} \mathrm{C}\right)$. The electrodes were assembled in coin cell (CR2032) using Whatman ${ }^{\circledR}$ glass microfiber filters as a separator using drop of electrolyte 1-Ethyl-3-methylimidazolium bis(trifluoromethylsulfonyl)imide in polycarbonate $1 \mathrm{M}$.

\section{Results}

The copper sulfide nanowires $\left(\mathrm{Cu}_{2-\mathrm{S}} \mathrm{SNWs}\right.$ ) were synthesized by sulphidation of high-quality CuNWs. We employed a facile procedure in which thiourea was used as a source of sulfur, instead of the more 
toxic and reactive $\mathrm{Na}_{2} \mathrm{~S}$. In particular, the CuNWs were treated with a diluted ethanolic solution of thiourea heated at $80^{\circ} \mathrm{C}$ for two hours. Heating is necessary to activate the reaction with thiourea, ${ }^{11}$ the conversion of the CuNWs into $\mathrm{Cu}_{2-\mathrm{x}} \mathrm{SNWs}$ is made possible by the thin layer of $\mathrm{CuO}$ which coats the synthesized CuNWs. ${ }^{10}$ In Figure 1a-b displays optical micrograph and scanning electron microscopy (SEM) images of the nanowires. They reveal that the NWs preserve a high aspect ratio, with lengths in the range $20-200 \mu \mathrm{m}$ and an average diameter of $98 \pm 17 \mathrm{~nm}$ as determined on 105 individual wires. Interestingly, when the reaction was conducted in water instead of ethanol, a fragmentation of the nanowires, with consequent reduction of the aspect-ratio, was observed (Figure S1 of the SI). Magnified SEM image (Figure 1c) depicts that the surface of the nanowire is covered by nanoplates of copper sulfide. The transmission electron microscopy (TEM) image shows that the nanowires present a core-shell structure, with a darker contrast in the outer shell and brighter one in the center (Figure 1d). In addition, the high-resolution TEM (HRTEM) image (Figure 1e) displays characteristic lattice fringes that demonstrate the presence of crystallized structures associated to grains with various morphologies and orientations with sizes of $10-20 \mathrm{~nm}$. The polycrystalline composition of the $\mathrm{Cu}_{2-}$ ${ }_{x} S N W s$ is confirmed also by selected area electron diffraction (SAED) pattern (Figure 1f), which exhibits the combination of discrete spots and concentric rings.
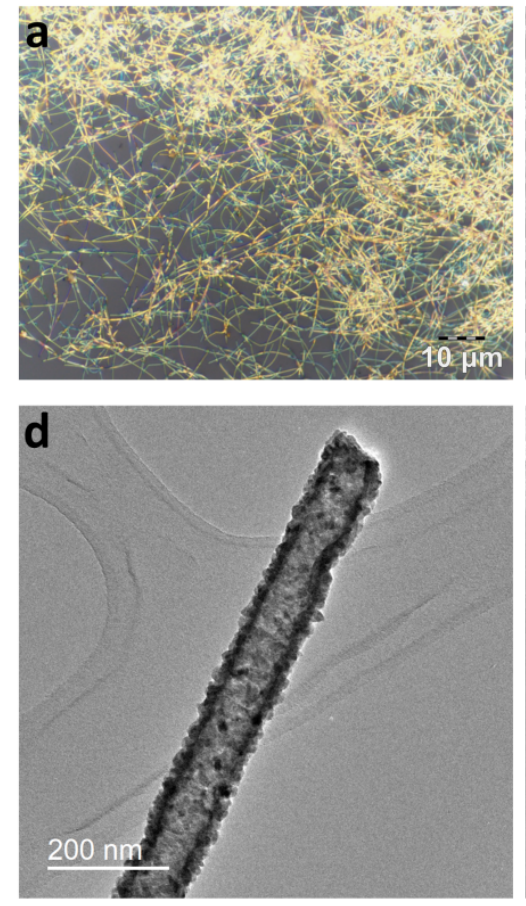
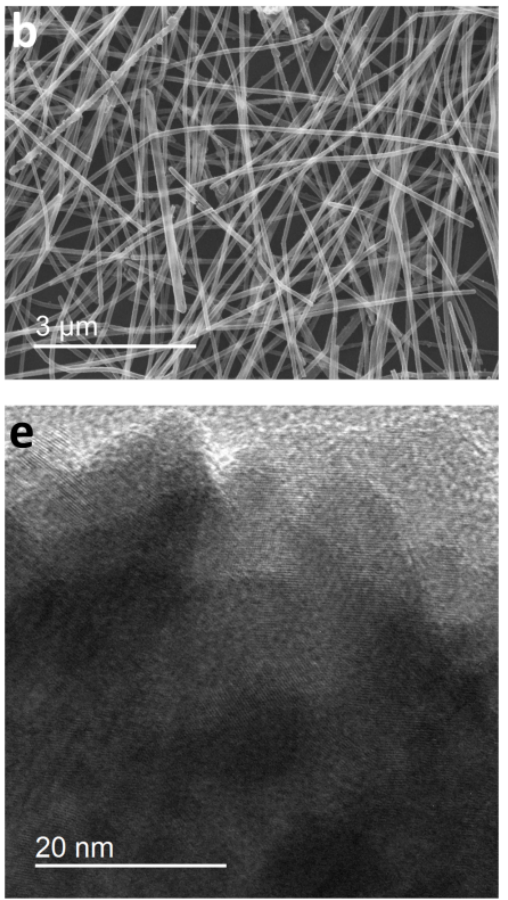

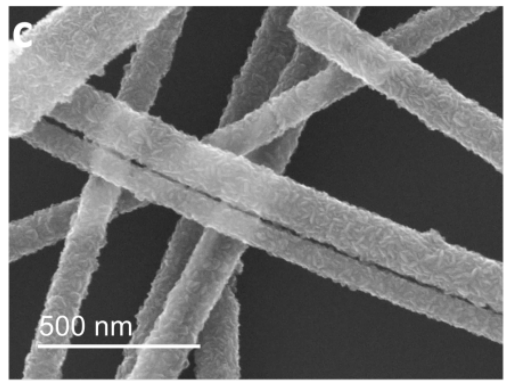

f

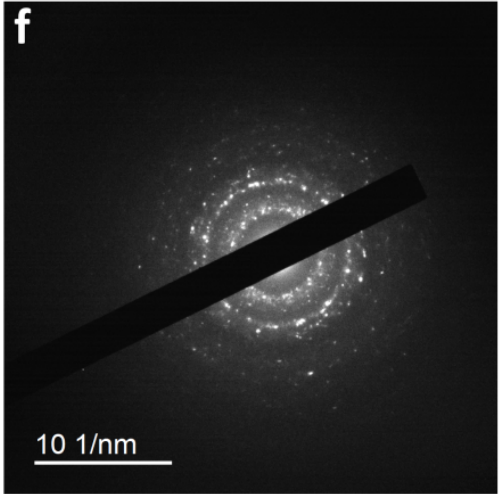

Figure 1. (a) Optical micrograph, (b-c) SEM, (d) TEM, (e) HRTEM images of the synthesized $\mathrm{Cu}_{2-x}$ SNWs. (f) SAED pattern of the area in (e), highlighting the presence of crystallized grains and the polycrystalline feature of the chosen area

The chemical composition of the nanowires was investigated by both Energy dispersive X-Ray Analysis (EDX) and X-Ray Photoelectron spectroscopy. The EDX mapping provided evidence for the presence of both copper and sulfur on all the nanowire section, with no appreciable differences between the outer and inner part (Figure S2a of the SI) while EDX spectrum shows the presence of copper and sulfur, in addition to small quantities of carbon, nitrogen and oxygen, with a Cu:S ratio of 1.57 (Figure $\mathrm{S} 2 \mathrm{~b}$ of the $\mathrm{SI}$ ). The fitting of the survey spectra of XPS analysis (Figure S3 of the SI) provides a similar $\mathrm{Cu}: \mathrm{S}$ ratio of 1.55. Figure 2a portrays a high-resolution spectrum of $\mathrm{Cu} 2 \mathrm{p}$ peak of the copper sulfide nanowires. The $\mathrm{Cu} 2 \mathrm{p}_{3 / 2}$ peak has a chemical shift of $932.4 \mathrm{eV}$, which is representative of $\mathrm{Cu}(\mathrm{I})$ of both 
CuS and $\mathrm{Cu}_{2} \mathrm{~S} .{ }^{12-13}$ The broad peaks at 945 and $963 \mathrm{eV}$ are weak satellite peaks, which can be likely ascribed to some $\mathrm{Cu}^{2+}$ surface impurities, while the pronounced tails of $\mathrm{Cu} 2 \mathrm{p}_{3 / 2}$ and $2 \mathrm{p}_{1 / 2}$ are due to the metallic properties of copper sulphides. ${ }^{13}$ The Cu LMM Auger peak (Figure S4 of the SI) falls at $568.7 \mathrm{eV}$, which is a typical value for CuS. ${ }^{14}$ Figure $2 \mathrm{~b}$ depicts the deconvoluted peak of Sp. Each component of the spectrum is split in two peaks $\left(p_{3 / 2}\right.$ and $\left.p_{1 / 2}\right)$ for the spin-orbit coupling $(\Delta e=1.16$ $\mathrm{eV}$ ). The components at 161.3 and $162.8 \mathrm{eV}$ belong to the species $\mathrm{S}^{2-}$ and $\mathrm{S}_{2}{ }^{2-}$ which can be found in all copper sulphides. ${ }^{15-16}$ Another split component is visible at $167.9 \mathrm{eV}$ and is due to some sulfate (probably from decomposition of thiourea) present on the surface of the nanowires. The Raman spectrum (Figure 2c) further confirms the composition of the nanowires; in fact, the intense peak at $473 \mathrm{~cm}^{-1}$ is due to S-S stretching and the weaker peak at $264 \mathrm{~cm}^{-1}$ belongs to Cu-S vibration. ${ }^{17-18}$ In particular, the peak shifts are characteristics of the covellite (CuS) structure. ${ }^{19}$ The presence of covellite phase is confirmed also by X-Ray powder diffraction (XRD). Moreover, the diffractograms of the nanowires evidence the presence of also another crystalline phase, which can be identified as roxbyite $\left(\mathrm{Cu}_{1.8} \mathrm{~S}\right) .{ }^{20-21}$ The presence of two crystalline phases would explain also why the stoichiometric ratio $\mathrm{Cu}: \mathrm{S}$ measured was 1.55 . Furthermore, the absence of the $\mathrm{Cu}(111)$ peak at $2 \theta=43.3^{\circ}$ and $\mathrm{Cu}(200)$ peak at $50.4^{\circ}$, which are typical of metallic CuNWs, indicates a total conversion of the copper(0) in $\mathrm{Cu}_{2}$ ${ }_{x} \mathrm{~S}^{22-23}$ To confirm the core-shell structure of the $\mathrm{Cu}_{2-\mathrm{x}} \mathrm{SNWs}$, we acquired the XPS spectra of the nanowires while etching their surface with an argon ion beam. It is possible to see that the peaks belonging to sulfate at $168 \mathrm{eV}$ in the S $2 p$ spectra (Figure S5a of the SI) and the satellite peaks due to $\mathrm{Cu}^{2+}$ in the $\mathrm{Cu} 2 \mathrm{p}$ spectra (Figure S5b of the $\mathrm{SI}$ ) disappear already after the first etching cycle, thus confirming that the contamination involves just a thin layer of the surface. Similarly, the foreign elements $\mathrm{C}, \mathrm{N}$ and $\mathrm{O}$ also disappear after the first etching cycles (Figure $\mathrm{S} 5 \mathrm{C}$ of the $\mathrm{SI}$ ). Moreover, the atomic abundance ratio between $\mathrm{Cu}$ and $\mathrm{S}$ increases from 1.04 to 1.72 with increasing the etching time (Figure $\mathrm{S} 5 \mathrm{~d}$ of the $\mathrm{SI}$ ), thus supporting the hypothesis of core-shell nanowires composed by an outer core of covellite and an inner core of roxbyite.

The absorption spectra of the $\mathrm{Cu}_{2-x} \mathrm{SNW}$ dispersed in ethanol was used to evaluate the optical bandgap (Figure $\mathrm{S} 6$ of the $\mathrm{SI}$ ). The nanowires exhibit a maximum of absorbance at $397 \mathrm{~nm}$. The energy of the optical direct and indirect bandgaps, computed from the Tauc plot (Figure S7 of the SI) amount to $2.0 \mathrm{eV}$ and $1.27 \mathrm{eV}$ respectively, in line with reported values for $\mathrm{CuS}$ and $\mathrm{Cu}_{1.8} \mathrm{~S}^{24-25} \mathrm{We}$ also measured the ionization potential (IP) of the $\mathrm{Cu}_{2-x} \mathrm{SNWs}$ deposited on a $\mathrm{Si} / \mathrm{SiO}_{2}$ substrate by photoemission spectroscopy in air (Figure S8 of the SI) which resulted $4.80 \pm 0.02$. 
a

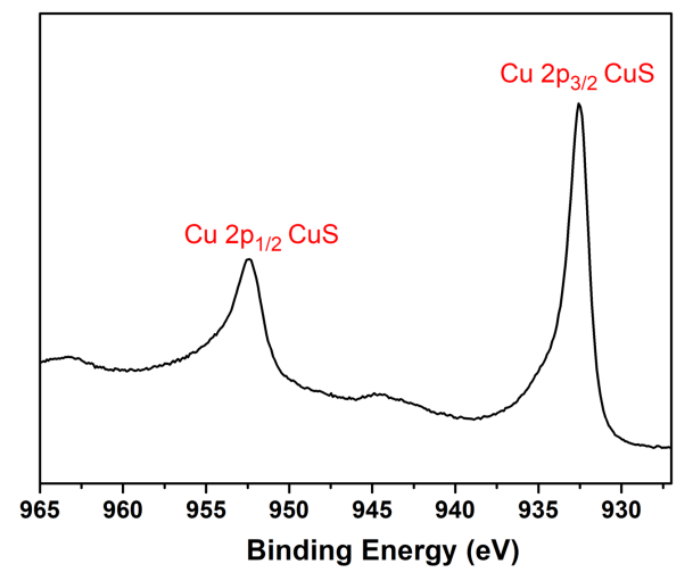

C

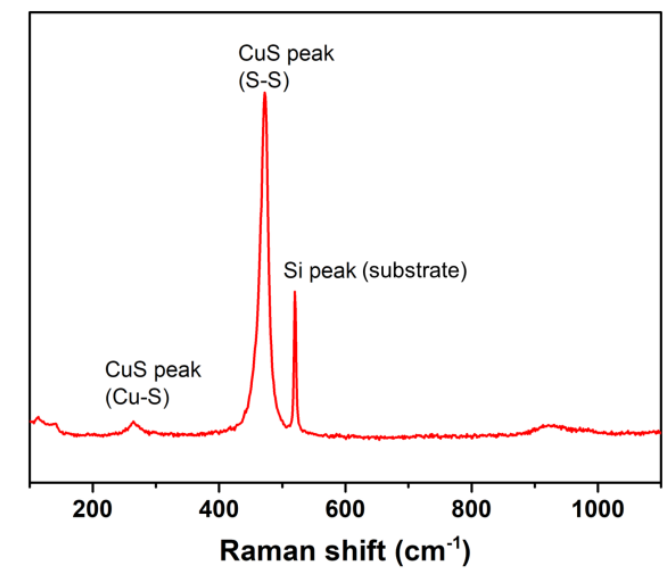

b

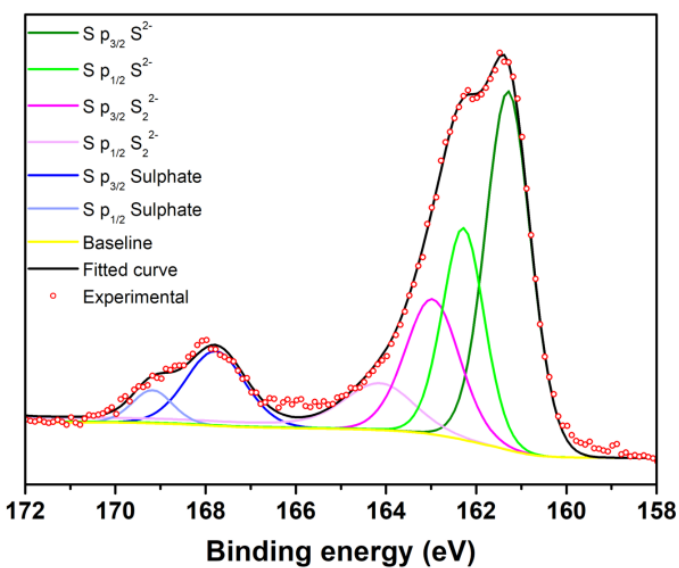

d

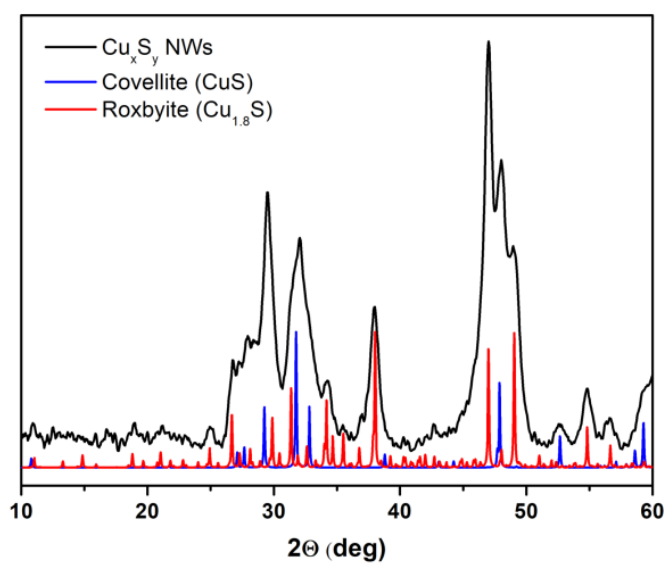

Figure 2. Characterization of the chemical composition. XPS spectra of (a) $\mathrm{Cu} 2 \mathrm{p}$ and (b) $\mathrm{S} p$ of $\mathrm{Cu}_{2-x} \mathrm{SNWs}$. (c) Raman spectrum, and (d) XRD powder diffractogram of $\mathrm{Cu}_{2-x} \mathrm{SNWs}$.

The $\mathrm{Cu}_{2-\mathrm{x}} \mathrm{SNWs}$ were then tested as transparent conductive films. The nanowires could be uniformly deposited onto glass, plastic, and paper substrates readily from ethanolic dispersion by using a commercial airbrush. Interestingly, the films were already conductive, immediately after the spraydeposition, without needing any post-treatment such as annealing under reducing atmosphere or chemical reduction. We tested the I-V characteristic of a conductive $\mathrm{Cu}_{2-x} \mathrm{SNWs}$ film deposited on a $5 \times 1.5 \mathrm{~cm}^{2}$ foil of polyethylene naphthalate (PEN) $125 \mu \mathrm{m}$ thick by connecting two electrodes made with copper tape. The film presented a perfectly Ohmic conductivity, with a resistance of $3.8 \mathrm{k} \Omega$ (figure $\mathrm{S} 9$ of the $\mathrm{SI}$ ). Then, we tested the flexibility of the film, by performing 10000 bending cycles with a bending radius of $8 \mathrm{~mm}$ (Figure S10 of the SI). The resistance of the film revealed an increase of only $4.4 \%$ after 10000 bending cycles. We also manually tested the static bending of the film with different radii (Figure 3a). No appreciable changes in the resistance were detected up to $1 \mathrm{~cm}$ of bending radius, followed by an increase of the resistance, which reaches $4.7 \%$ at a bending radius of $2.5 \mathrm{~mm}$.

Subsequently, we spray-coated different amounts of $\mathrm{Cu}_{2-x} \mathrm{SNWs}$ dispersed in ethanol onto glass substrates, and we measured the sheet resistance and transmittance of the films. The measured sheet resistance of the films as a function of their transmittance at $550 \mathrm{~nm}$ is reported in Figure $3 \mathrm{~b}$. The corresponding transmittance spectra, photos and microphotographs of the conductive films are reported in Figure S11 of the SI. The sheet resistance decreases by several orders of magnitude passing from $90 \%$ transmittance to $80 \%$. At $73.7 \%$ of transmittance (at $550 \mathrm{~nm}$ ) the sheet resistance of the film is $4.1 \mathrm{k} \Omega / \mathrm{sq}$, hence being around 50-100 times higher than for films of CuNWs after annealing or 
chemical reduction. ${ }^{5,10,26}$ Thick films made by filtration (34 $\pm 4 \mu \mathrm{m}$ thick) presented a sheet resistance of $15 \pm 2 \Omega / s q$ which corresponds to a bulk resistivity of $5 \times 10^{-4} \Omega \cdot m$. However, compared to CuNWs, these copper sulfide nanowires display a much higher chemical stability, in particular to acid and oxidative environments. Spray coated films of $\mathrm{Cu}_{2-\mathrm{S}} \mathrm{SNWs}$ onto glass substrates were soaked into a $\mathrm{FeCl}_{3} 50 \mathrm{mM}, \mathrm{HCl} 1 \mathrm{M}$ and $\mathrm{NaOH} 1 \mathrm{M}$ solutions for 24 hours at room temperature (Figure 3c). The sheet resistance of the film exposed to the oxidizing $\mathrm{FeCl}_{3}$ increased of 15 times over 24 hours, while the sheet resistance of the film exposed to acidic environment presented a 3-fold increase over 24 hours. In both cases the transmittance (at $465 \mathrm{~nm}$ ) of the films after $24 \mathrm{~h}$ increased of ca. $6 \%$ because of the corrosion (Figure S12a-c of the SI). In comparison, films of CuNWs on glass were completely dissolved by $\mathrm{FeCl}_{3}$ and $\mathrm{HCl}$ in less than 30 seconds and 5 min of exposure, respectively. Nevertheless, the stability of the $\mathrm{Cu}_{2-x} \mathrm{SNWs}$ to $\mathrm{NaOH} 1 \mathrm{M}$ was lower, with complete loss of the conductivity and dissolution of the film after 4 hours of exposure (Figure $\mathrm{S} 12 \mathrm{~d}$ of the $\mathrm{SI}$ ).

We have annealed the film under nitrogen at different temperatures to evaluate the effect of the annealing on the conductivity of the film. We noticed a 2-fold decrease of the sheet resistance of the film (from $1.24 \pm 0.07 \mathrm{k} \Omega / \mathrm{sq}$ to $632 \pm 28 \Omega / \mathrm{sq}$ ) after $30 \mathrm{~min}$ of annealing at $190{ }^{\circ} \mathrm{C}$. To check if this decrease in resistance was due to a crystal phase transition, we performed differential scanning calorimetry (DSC) on the $\mathrm{Cu}_{2-x} \mathrm{SNWs}$ under nitrogen flux (Figure S13a of the $\mathrm{SI}$ ). We found an endothermic peak at $189^{\circ} \mathrm{C}$, which can be ascribed to a crystal phase transition. However, XPS analysis performed after the annealing suggests that the increase in conductivity may be due to desorption of the contaminants and removal of the surface oxidized layer (Figure S14 of the SI). The thermogravimetric analysis of the nanowires made it possible to assess their thermal stability in air (Figure $\mathrm{S} 13 \mathrm{~b}$ of the $\mathrm{SI}$ ). The $\mathrm{Cu}_{2-\mathrm{x}} \mathrm{SNWs}$ present a steep mass loss at $275^{\circ} \mathrm{C}$, probably determined by the conversion of the external $\mathrm{CuS}$ into $\mathrm{Cu}_{2} \mathrm{~S}$ and release of $\mathrm{SO}_{2}$, followed by a first increase of mass $(+23 \%)$ at $305^{\circ} \mathrm{C}$, due to oxidation to copper sulfate, and a second increase of mass $(+6 \%)$ at $480{ }^{\circ} \mathrm{C}$, due to formation of $\mathrm{CuO} \cdot \mathrm{CuSO}_{4}$. Finally, at $550{ }^{\circ} \mathrm{C}$ the mass starts to decrease because of the conversion to $\mathrm{CuO}$ and release of $\mathrm{SO}_{2}{ }^{27}$

The electrical characterization was performed also on a single $\mathrm{Cu}_{2-\mathrm{x}} \mathrm{SNW}$. We evaporated two gold top electrodes on a single $\mathrm{Cu}_{2-\mathrm{x}} \mathrm{SNW}$ by direct laser lithography (Figure $\mathrm{S} 15$ of the $\mathrm{SI}$ ). Also in this case, the conduction was perfectly Ohmic (Figure $3 \mathrm{~d}$ ). The measured resistance of the single wire amounted to $16.9 \pm 0.1 \mathrm{k} \Omega$. The length and diameter of the nanowire were measured by SEM and resulted in $18.1 \pm 0.3 \mu \mathrm{m}$ and $97.6 \pm 3.3 \mathrm{~nm}$. This made it possible to calculate the resistivity of the single nanowire, which was resulted $6.9 \times 10^{-6} \Omega \cdot \mathrm{m}$. The lower value compared to the bulk resistivity can be attributed to the absence of the contact resistance between nanowires in the single nanowire measurement. For 
comparison, a single CuNW of similar aspect ratio has been reported having a resistivity 43 times lower. ${ }^{28}$
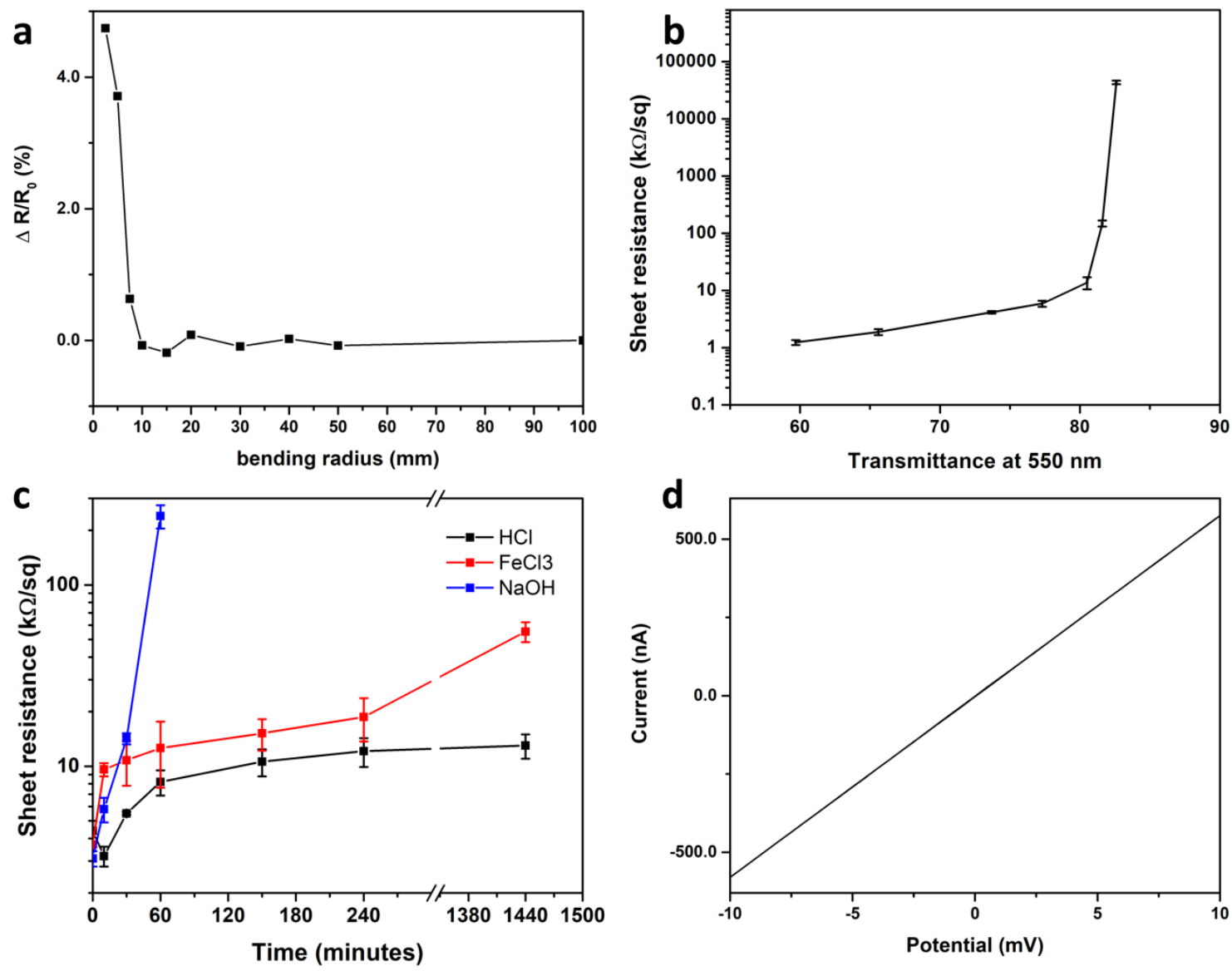

Figure 3. (a) Change in sheet resistance of a $5 \times 1.5 \mathrm{~cm}^{2}$ conductive film of spray-coated $\mathrm{Cu}_{2-x} \mathrm{SNWs}$ on PEN $(125 \mu \mathrm{m})$ as a function of the bending radius. (b) Sheet resistance of spray-coated $\mathrm{Cu}_{2-x} \mathrm{SNWs}$ on glass as a function of their transmittance at $550 \mathrm{~nm}$. (c) Sheet resistance 3 different films of spray-coated $\mathrm{Cu}_{2-x} \mathrm{SNWs}$ on glass as function of soaking time into water solutions of $\mathrm{HCl} 1 \mathrm{M}$ (black curve), $\mathrm{FeCl}_{3} 50 \mathrm{mM}$ (red curve) and $\mathrm{NaOH} 1 \mathrm{M}$ (blue curve). Current as a function of the potential applied to a single $\mathrm{Cu}_{2-\mathrm{x}} \mathrm{SNW}$.

Copper sulfide nanostructures were found being promising electrode materials for supercapacitors. ${ }^{29}$ Since $\mathrm{Cu}_{2-x} \mathrm{SNW}$ s could benefit from their large specific surface area, we tested them as electrode material for supercapacitors. The $\mathrm{Cu}_{2-x} \mathrm{SNW}$ s were deposited on a carbon foil substrate and used as electrodes in a solid-state symmetric supercapacitor in which 1-Ethyl-3-methylimidazolium bis(trifluoromethylsulfonyl)imide $1 \mathrm{M}$ in polycarbonate was used as electrolyte. The use of an organic electrolyte and of an aprotic ionic liquid allowed to extend the potential window up to $2.5 \mathrm{~V}$. We performed cyclic voltammetry (CV) analyses between 0 and $2.5 \mathrm{~V}$ at different scan rates, ranging from $5 \mathrm{mV} \cdot \mathrm{s}^{-1}$ to $2000 \mathrm{mV} \cdot \mathrm{s}^{-1}$ (Figure $4 \mathrm{a}$ and Figure S16 of the SI). The analysis of curves at lower scan rates clearly depicts pseudocapacitive behaviour indicating a significant contribution of Faradaic reactions in storage mechanism (Figure 4b). The presence of peaks around 1.0 and $1.5 \mathrm{~V}$ can be attributed to oxidation between $\mathrm{Cu}_{1.8} \mathrm{~S}$ and $\mathrm{CuS}$, followed by the oxidation of $\mathrm{S}^{-}$to $\mathrm{S}^{0}{ }^{30-32}$ At higher scan rates the redox peaks become less pronounced and the curves acquire a quasi-rectangular shape, indicating that the capacitance of the pseudocapacitor becomes dominated by the double-layer effect, due to the fast polarization of electrolyte ions on electrodes surfaces. The slow diffusion of the large electrolyte ions into the nanostructured electrode is responsible of the diminished Faradaic 
component. The highest specific capacitance of $324 \mathrm{~F} \cdot \mathrm{g}^{-1}$ was obtained at scan rates of $5 \mathrm{mV} \cdot \mathrm{s}^{-1}$, which is similar to the one of a previously reported solid state supercapacitor based on $\mathrm{Cu}_{7} \mathrm{~S}_{4} \mathrm{NWs}^{33}$ The volumetric capacitance and energy density of the electrode were estimated as $60.5 \mathrm{~F} \cdot \mathrm{cm}^{-3}$ and 52.5 $\mathrm{mWh} \mathrm{cm}{ }^{-3}$, respectively (at scan rates of $5 \mathrm{mV} \cdot \mathrm{s}^{-1}$ ). To the best of our knowledge these values are the highest reported for supercapacitors based on copper sulfides nanostructures. ${ }^{34-36}$ However, due to the slow diffusion of the electrolyte, the material shows an important drop of the specific capacity at higher scan rates $\left(40.3 \mathrm{~F} \cdot \mathrm{g}^{-1}\right.$ at $1000 \mathrm{mV} \cdot \mathrm{s}^{-1}$ ) (Figure $4 \mathrm{c}$ and Table S1 of the SI). Notably, the material exhibited moderate capacitance retention of $70 \%$ of initial capacitance, dropping from $91.3 \mathrm{~F} \cdot \mathrm{g}^{-1}$ to 64 $\mathrm{F} \cdot \mathrm{g}^{-1}$ after 5000 cycles while tested at $100 \mathrm{mV} \cdot \mathrm{s}^{-1}$ (Figure $4 \mathrm{~d}$ and Figure S17a of the SI), which is comparable to similar copper sulfides nanostructures. ${ }^{30-31}$ Such a drop mainly occurs during the first 1000 cycles, and it is followed by a stabilization of the capacitance, thus suggesting the formation of an irreversibly oxidized passivation layer which protects the rest of the active material. The distorted shape of GCD curves (Figure S17b of the SI) also confirms pseudocapacitive behavior which can be additionally supported by redox active electrolyte which was previously reported for bis(trifluoromethylsulfonyl)imide anion. ${ }^{37}$ The Nyquist plot (Figure S17c of the SI) revealed solution resistance of $5.8 \Omega$, comparable with other ionic liquid electrolyte- based devices ${ }^{38-39}$ and the Warburg resistance of $25 \Omega$ corresponding to ion transfer on electrolyte- $\mathrm{Cu}_{2-x} \mathrm{SNWs}$ electrode interface and suggests that dense packing of nanowires might slightly restrict easy ion migration through the electrode. ${ }^{30}$
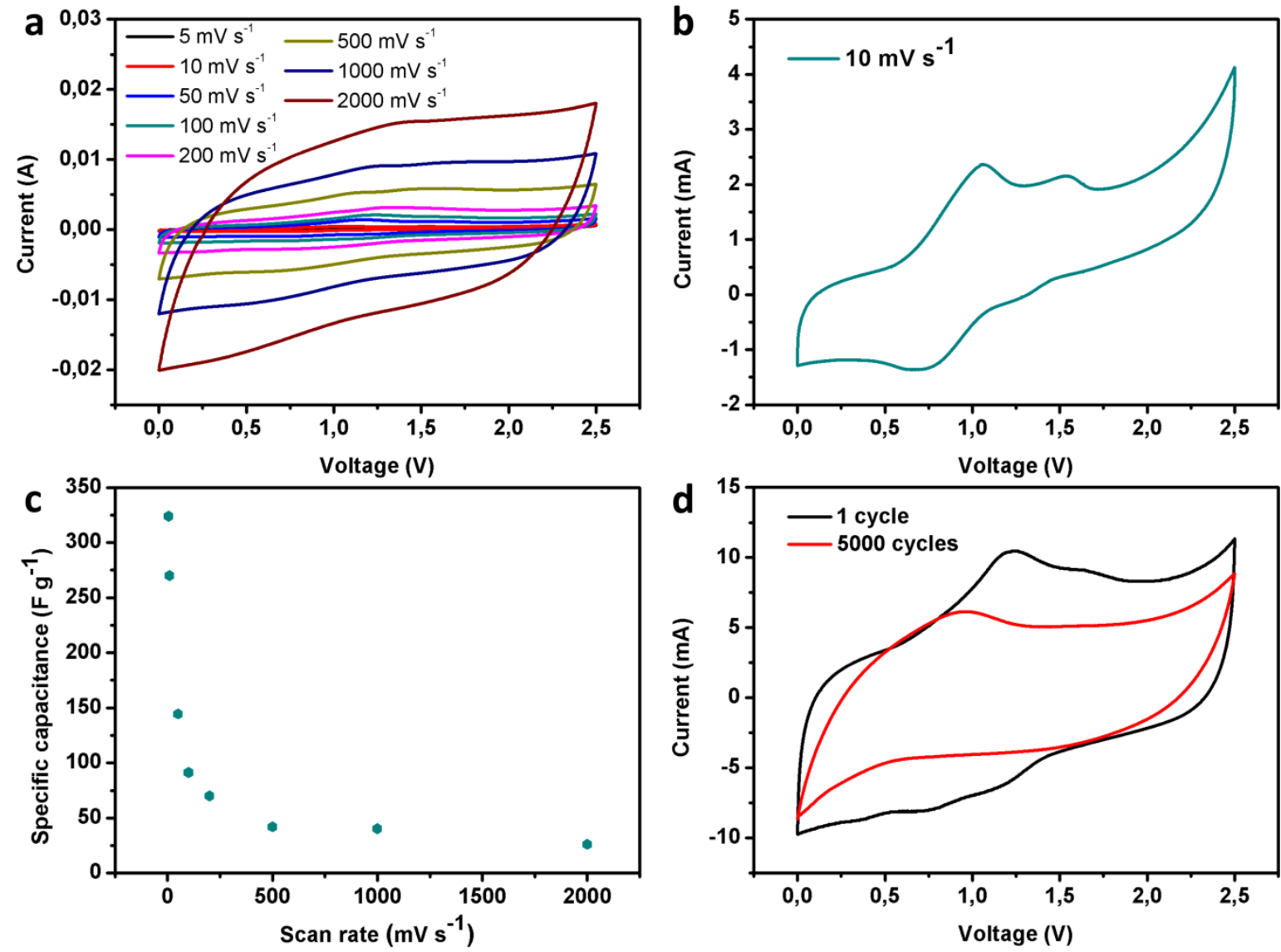

Figure 4. (a) Cyclic voltammetry (CV) curves of the $\mathrm{Cu}_{2-\mathrm{x}} \mathrm{SNWs}$ based supercapacitor at different scan rates (from $5 \mathrm{mV} \cdot \mathrm{s}^{-1}$ to $2000 \mathrm{mV} \cdot \mathrm{s}^{-1}$ ) and (b) detail of the CV performed at $10 \mathrm{mV} \cdot \mathrm{s}^{-1}$. (c) Calculated specific capacitance of the supercapacitor at different scan rates. (d) CV of the supercapacitor at the $1^{\text {st }}$ and $5000^{\text {th }}$ cycle (scan rate: $100 \mathrm{mV} \cdot \mathrm{s}^{-1}$ ). 


\section{Conclusions}

In summary, we have demonstrated that ultralong copper nanowires (CuNWs) can be converted into copper sulfide nanowires ( $\mathrm{Cu}_{2-x} \mathrm{SNWs}$ ) maintaining the high aspect ratio by sulphidation in ethanolic solution employing thiourea as sulfur source. The multiscale characterization of $\mathrm{Cu}_{2-\mathrm{x}} \mathrm{SNWs}$ by means of XRD, TEM, EDX and XPS, revealed that after sulphidation a core shell structure is obtained with the outer core being composed by covellite and the inner core by roxbyite. The obtained $\mathrm{Cu}_{2-x} \mathrm{SNWs}$ could be readily dispersed in ethanol and be directly deposited by spray-coating onto glass or plastic substrate resulting in conductive films without the need of any post deposition process. Because of the high aspect ratio of the synthesized $\mathrm{Cu}_{2-x} \mathrm{SNWs}$, films deposited on glass revealed a sheet resistance as low as $4.1 \mathrm{k} \Omega / \mathrm{sq}$ at $73.7 \%$ transmittance (measured at $550 \mathrm{~nm}$ ), which can be further halved after annealing of the film at $190{ }^{\circ} \mathrm{C}$ for $30 \mathrm{~min}$. The film possesses an improved chemical stability in presence of copper etchants such as $\mathrm{FeCl}_{3}$, as well as in acidic conditions. Bending tests have also shown a remarkable stability with an increase of the resistance of only $4.4 \%$ after 10000 bending cycles. The electronic conductivity of the material has been determined not only on the film as a function of light transmission, but also in the bulk and at a single nanowire level. The latest exhibited a perfect Ohmic conductivity with a resistivity of $6.9 \times 10^{-6} \Omega \cdot \mathrm{m}$. Finally, the performance of the material in a symmetric supercapacitor has been evaluated. The $\mathrm{Cu}_{2-x} \mathrm{SNWs}$ presented a pseudocapacitive behavior, with a high specific capacity of $324 \mathrm{~F} \cdot \mathrm{g}^{-1}$ and an ultrahigh volumetric capacity of $60.5 \mathrm{~F} \cdot \mathrm{cm}^{-3}$ at scan rates of $5 \mathrm{mV} \cdot \mathrm{s}^{-1}$. The supercapacitor also revealed a moderate capacity retention after 5000 cycles of operation at $100 \mathrm{mV} \cdot \mathrm{s}^{-1}$ (70\% of the original capacitance). Our results suggest that $\mathrm{Cu}_{2-x} \mathrm{SNWs}$ can be used for printed, flexible electronics while their use as transparent electrodes still require an improvement of the conductivity to be comparable with metallic CuNWs.

\section{Conflicts of interest}

The authors declare no competing financial interest.

\section{Acknowledgements}

We acknowledge financial support from the European Commission through the H2020 project DECOCHROM (GA-760973), the ERC project SUPRA2DMAT (GA- 833707), the Agence Nationale de la Recherche through the Labex project CSC (ANR-10-LABX-0026 CSC) within the Investissement d'Avenir program (ANR-10- 120 IDEX-0002-02), the International Center for Frontier Research in Chemistry (icFRC) as well as the Institut Universitaire de France (IUF) and the National Science Center (Grant No. 2019/35/B/ST5/01568 and Grant No. 2019/33/N/ST5/00052).

\section{References}

1. Wu, Z.; Chen, Z.; Du, X.; Logan, J. M.; Sippel, J.; Nikolou, M.; Kamaras, K.; Reynolds, J. R.; Tanner, D. B.; Hebard, A. F.; Rinzler, A. G. Transparent, Conductive Carbon Nanotube Films. Science 2004, 305 (5688), 1273-1276. 
2. Souza, V. H. R.; Husmann, S.; Neiva, E. G. C.; Lisboa, F. S.; Lopes, L. C.; Salvatierra, R. V.; Zarbin, A. J. G. Flexible, Transparent and Thin Films of Carbon Nanomaterials as Electrodes for Electrochemical Applications. Electrochim. Acta 2016, 197, 200-209.

3. Ye, S.; Rathmell, A. R.; Chen, Z.; Stewart, I. E.; Wiley, B. J. Metal Nanowire Networks: The Next Generation of Transparent Conductors. Adv. Mater. 2014, 26 (39), 6670-6687.

4. Zhang, T.; Zhao, M.; Daneshvar, F.; Xia, F.; Sue, H.-J. Solution-Processable Oxidation-Resistant Copper Nanowires Decorated with Alkyl Ligands. ACS Appl. Nano Mater. 2019, 2 (12), 7775-7784.

5. Nam, V. B.; Lee, D. Copper Nanowires and Their Applications for Flexible, Transparent Conducting Films: A Review. Nanomaterials 2016, 6 (3).

6. Rathmell, A. R.; Nguyen, M.; Chi, M.; Wiley, B. J. Synthesis of Oxidation-Resistant Cupronickel Nanowires for Transparent Conducting Nanowire Networks. Nano Lett. 2012, 12 (6), 3193-3199.

7. Chen, Z. F.; Ye, S. R.; Stewart, I. E.; Wiley, B. J. Copper Nanowire Networks with Transparent Oxide Shells That Prevent Oxidation without Reducing Transmittance. ACS Nano 2014, 8 (9), 96739679.

8. Shamraiz, U.; Hussain, R. A.; Badshah, A. Fabrication and applications of copper sulfide (CuS) nanostructures. J. Solid State Chem. 2016, 238, 25-40.

9. Chung, J. S.; Sohn, H. J. Electrochemical behaviors of CuS as a cathode material for lithium secondary batteries. J. Power Sources 2002, 108 (1-2), 226-231.

10. Aliprandi, A.; Moreira, T.; Anichini, C.; Stoeckel, M.-A.; Eredia, M.; Sassi, U.; Bruna, M.; Pinheiro, C.; Laia, C. A. T.; Bonacchi, S.; Samorì, P. Hybrid Copper-Nanowire-Reduced-Graphene-Oxide Coatings: A "Green Solution" Toward Highly Transparent, Highly Conductive, and Flexible Electrodes for (Opto)Electronics. Adv. Mater. 2017, 29 (41), 1703225.

11. Hendricks, M. P.; Campos, M. P.; Cleveland, G. T.; Jen-La Plante, I.; Owen, J. S. A tunable library of substituted thiourea precursors to metal sulfide nanocrystals. Science 2015, 348 (6240), 1226-1230. 12. Goh, S. W.; Buckley, A. N.; Lamb, R. N. Copper(II) sulfide? Miner. Eng. 2006, 19 (2), 204-208.

13. Folmer, J. C. W.; Jellinek, F. The valence of copper in sulphides and selenides: An X-ray photoelectron spectroscopy study. J. Less-Common Met. 1980, 76 (1-2), 153-162.

14. Krylova, V.; Andrulevičius, M. Optical, XPS and XRD Studies of Semiconducting Copper Sulfide Layers on a Polyamide Film. Int. J. Photoenergy 2009, 2009, 1-8.

15. Karikalan, N.; Karthik, R.; Chen, S.-M.; Karuppiah, C.; Elangovan, A. Sonochemical Synthesis of Sulfur Doped Reduced Graphene Oxide Supported CuS Nanoparticles for the Non-Enzymatic Glucose Sensor Applications. Sci. Rep. 2017, 7 (1).

16. Estrada, A. C.; Silva, F. M.; Soares, S. F.; Coutinho, J. A. P.; Trindade, T. An ionic liquid route to prepare copper sulphide nanocrystals aiming at photocatalytic applications. RSC Adv. 2016, 6 (41), 34521-34528.

17. Thongtem, T.; Phuruangrat, A.; Thongtem, S. Characterization of copper sulfide nanostructured spheres and nanotubes synthesized by microwave-assisted solvothermal method. Mater. Lett. 2010, 64 (2), 136-139.

18. Chaki, S. H.; Tailor, J. P.; Deshpande, M. P. Covellite CuS - Single crystal growth by chemical vapour transport (CVT) technique and characterization. Mater. Sci. Semicond. Process. 2014, 27, $577-$ 585.

19. Ishii, M.; Shibata, K.; Nozaki, H. Anion Distributions and Phase Transitions in CuS1-xSex(x = 01) Studied by Raman Spectroscopy. J. Solid State Chem. 1993, 105 (2), 504-511.

20. Mumme, W. G.; Gable, R. W.; Petricek, V. THE CRYSTAL STRUCTURE OF ROXBYITE, Cu58S32. The Canadian Mineralogist 2012, 50 (2), 423-430.

21. Tezuka, K.; Sheets, W. C.; Kurihara, R.; Shan, Y. J.; Imoto, H.; Marks, T. J.; Poeppelmeier, K. R. Synthesis of covellite (CuS) from the elements. Solid State Sci. 2007, 9 (1), 95-99.

22. Mohl, M.; Pusztai, P.; Kukovecz, A.; Konya, Z.; Kukkola, J.; Kordas, K.; Vajtai, R.; Ajayan, P. M. Low-Temperature Large-Scale Synthesis and Electrical Testing of Ultralong Copper Nanowires. Langmuir 2010, 26 (21), 16496-16502. 
23. Zhang, T.; Hsieh, W.-Y.; Daneshvar, F.; Liu, C.; Rwei, S.-P.; Sue, H.-J. Copper(i)-alkylamine mediated synthesis of copper nanowires. Nanoscale 2020, 12 (33), 17437-17449.

24. Safrani, T.; Jopp, J.; Golan, Y. A comparative study of the structure and optical properties of copper sulfide thin films chemically deposited on various substrates. RSC Adv. 2013, 3 (45), 23066.

25. Quintana-Ramirez, P. V.; Arenas-Arrocena, M. C.; Santos-Cruz, J.; Vega-González, M.; Martínez-Alvarez, O.; Castaño-Meneses, V. M.; Acosta-Torres, L. S.; de la Fuente-Hernández, J. Growth evolution and phase transition from chalcocite to digenite in nanocrystalline copper sulfide: Morphological, optical and electrical properties. Beilstein J. Nanotechnol. 2014, 5, 1542-1552.

26. Rathmell, A. R.; Bergin, S. M.; Hua, Y.-L.; Li, Z.-Y.; Wiley, B. J. The Growth Mechanism of Copper Nanowires and Their Properties in Flexible, Transparent Conducting Films. Adv. Mater. 2010, 22 (32), 3558-3563.

27. Nafees, M.; Ali, S.; Rasheed, K.; Idrees, S. The novel and economical way to synthesize CuS nanomaterial of different morphologies by aqueous medium employing microwaves irradiation. Applied Nanosci. 2011, 2 (2), 157-162.

28. Luo, B.; Fang, Y.; Li, J.; Huang, Z.; Hu, B.; Zhou, J. Improved Stability of Metal Nanowires via Electron Beam Irradiation Induced Surface Passivation. ACS Appl. Mater. Interfaces 2019, 11 (13), 12195-12201.

29. Sun, S.; Li, P.; Liang, S.; Yang, Z. Diversified copper sulfide (Cu2-xS) micro-/nanostructures: a comprehensive review on synthesis, modifications and applications. Nanoscale 2017, 9 (32), 1135711404.

30. Justin Raj, C.; Kim, B. C.; Cho, W.-J.; Lee, W.-G.; Seo, Y.; Yu, K.-H. Electrochemical capacitor behavior of copper sulfide (CuS) nanoplatelets. J. Alloys Compd. 2014, 586, 191-196.

31. Hsu, Y.-K.; Chen, Y.-C.; Lin, Y.-G. Synthesis of copper sulfide nanowire arrays for highperformance supercapacitors. Electrochim. Acta 2014, 139, 401-407.

32. Stević, Z.; Rajčić-Vujasinović, M. Chalcocite as a potential material for supercapacitors. J. Power Sources 2006, 160 (2), 1511-1517.

33. Javed, M. S.; Dai, S.; Wang, M.; Xi, Y.; Lang, Q.; Guo, D.; Hu, C. Faradic redox active material of CU7S4 nanowires with a high conductance for flexible solid state supercapacitors. Nanoscale 2015, 7 (32), 13610-13618.

34. Majumdar, D. Recent progress in copper sulfide based nanomaterials for high energy supercapacitor applications. J. Electroanal. Chem. 2021, 880, 114825.

35. Lee, Y.-W.; Kim, B.-S.; Hong, J.; Lee, J.; Pak, S.; Jang, H.-S.; Whang, D.; Cha, S.; Sohn, J. I.; Kim, J. M. A pseudo-capacitive chalcogenide-based electrode with dense 1-dimensional nanoarrays for enhanced energy density in asymmetric supercapacitors. J. Mater. Chem. A 2016, 4 (26), 10084-10090. 36. Ranjith Kumar, D.; Kesavan, S.; Baynosa, M. L.; Shim, J.-J. Flower-like Cu1.8S nanostructures for high-performance flexible solid-state supercapacitors. Appl. Surf. Sci. 2018, 448, 547-558.

37. Navalpotro, P.; Palma, J.; Anderson, M.; Marcilla, R. High performance hybrid supercapacitors by using para-Benzoquinone ionic liquid redox electrolyte. J. Power Sources 2016, 306, 711-717.

38. Maiti, S.; Pramanik, A.; Chattopadhyay, S.; De, G.; Mahanty, S. Electrochemical energy storage in montmorillonite $\mathrm{K} 10$ clay based composite as supercapacitor using ionic liquid electrolyte. J. Colloid Interface Sci. 2016, 464, 73-82.

39. Tiruye, G. A.; Muñoz-Torrero, D.; Palma, J.; Anderson, M.; Marcilla, R. Performance of solid state supercapacitors based on polymer electrolytes containing different ionic liquids. J. Power Sources 2016, 326, 560-568. 